\title{
IDENTIFICATION OF COMPLEX VOLATILE ORGANIC COMPOUNDS IN MUNICIPAL LANDFILL LEACHATE BY HEAD-SPACE SOLID PHASE MICROEXTRACTION AND GCXGC-qMS ANALYSIS
}

\author{
MIHAIL SIMION BELDEAN-GALEA ${ }^{\mathrm{a} *}$, DIDIER THÉBAUT ${ }^{\mathrm{b}}$, \\ JERÔME VIAL ${ }^{b}$, VIRGINIA COMAN ${ }^{\mathrm{c}}$
}

\begin{abstract}
A method for the identification of different classes of volatile organic compounds in the municipal landfill leachate using solid phase microextraction and comprehensive two dimensional gas chromatography coupled with mass spectrometry (SPME-GCxGC-qMS) is elaborated. The results showed that the proposed protocol is able to separate and identify in a single run different classes of volatile organic compounds responsible for the odor of leachate such as carbonyl compounds, aromatic compounds, terpenes, phenolic compounds and nitrogen and sulfur containing compounds. The use of solid phase microextraction not only eliminate the solvent from the samples processing step but also considerably reduces the time and the volume of the sample necessary for this step, being a viable green alternative for this type of analysis. The use of mass spectrometry gives the possibility to indentify many other compounds responsible for municipal landfill leachate odor, creating the premises for a better assessment of chemical composition of leachate. The developed protocol shows good performances in term of repeatability, linearity, limit of detection and limit of quantification being applicable for the real municipal landfill leachate analysis.
\end{abstract}

Keywords: Volatile organic compounds, municipal landfill leachate, solid phase microextraction, GCxGC-qMS

${ }^{a}$ Babeș-Bolyai University, Faculty of Environmental Science and Engineering, 30 Fântânele street, RO-400294, Cluj-Napoca, Romania.

* Corresponding author simion.beldean@yahoo.com

${ }^{b}$ École Supérieure de Physique et de Chimie Industrielles, 10 rue Vauquelin, 75231 Paris Cedex 05, France.

c Babeș-Bolyai University, Raluca Ripan Institute for Research in Chemistry, 30 Fântânele street, RO-400294 Cluj-Napoca, Romania. 


\section{INTRODUCTION}

Leachate is the liquid generated by the percolation of rainwater through the layers of wastes in municipal landfill site. This product can contain both organic and inorganic substances, released from the material deposited or as the result of biotic and abiotic reactions [1-2].

The basal composition of leachates is characterized by dissolved organic matter, xenobiotic organic compounds, inorganic salts, ammonia, heavy metals and other toxicants which are potentially harmful to human and animal health $[1,3]$.

More than 200 organic compounds have been identified as being dissolved in municipal landfill leachate with upwards of 35 compounds having the potential to cause harm to the environment and human health [4].

The most organic hazardous classes of compounds identified in the municipal landfill leachate are aromatic compounds, chlorinated aliphatic compounds, aliphatic and aromatic acids, polycyclic aromatic hydrocarbons, aldehydes, ketones, terpenes, phenols, phthalates, pesticides, nitrogen containing compounds, organo-phosphoric flame retardants, mercaptans etc. [5-7].

Near the dissolved chemical compounds, municipal landfills are also a potential source of offensive odors which make the areas in the proximity of landfills vulnerable not only to the emissions of potential toxic compounds but also to the nuisance such as odor pollution [8]. The odorous compounds generated by municipal landfill contain generally six classes of substances such as: saturated and unsaturated hydrocarbons, acidic hydrocarbons and organic alcohols, aromatic hydrocarbons, halogenated compounds, sulfur compounds (carbon disulfide and mercaptans), and inorganic compounds [7, 9]. Some of these compounds represent odors causing annoyance for the population, other compounds can be toxic for human and animal health (psychological stress, irritation of mucous membranes, long-term toxic reactions) [10] or can be precursors of photochemical smog formation [9]. From these reasons in the last decades many scientists have been paid attention to the characterization of volatile organic compounds emitted from the municipal landfill.

Over 500 compounds have been reported in landfill gas, these compounds including alkanes and alkenes, cycloalkanes and cycloalkenes, aromatic and polycyclic aromatic hydrocarbons and their derivatives, aldehydes, alcohols, ketones, esters, organohalogens and organosulphur compounds, trichlorethylene, tetrachlorethylene, $b$-pinenes, limonene, $p$-cymene etc. [11-13]. Usually the concentrations of the odorous compounds are very low, but their olfactory thresholds are in some cases lower. Hence, sensitive analytical methods are required for the identification and quantification of odorous substances taking into account that their concentrations are often below the detection limit of measuring equipment [14]. 
IDENTIFICATION OF COMPLEX VOLATILE ORGANIC COMPOUNDS IN MUNICIPAL LANDFILL ...

The aim of this study was to develop a sensitive and, in the same time, a comprehensive method for the identification of some classes of compounds responsible for the odor in municipal landfill leachate which may pose health concerns to nearby neighborhoods.

\section{RESULTS AND DISCUSSION}

\subsection{Analytical performances of the SPME-GCXGC-qMS method}

The performances of developed method were evaluated in term of repeatability (intra-day precision), linearity, limit of detection (LOD) and limit of quantification (LOQ) calculated based on the ratio of standard deviation (SD) and the slope of calibration curves (Table 1).

Table 1. The performances of developed SPME-GCxGC-MS method

\begin{tabular}{|c|c|c|c|c|c|c|c|}
\hline Compound name & $\begin{array}{l}\text { Linear curve } \\
\text { equations }\end{array}$ & $\mathrm{R}^{2}$ & SD & Slope & $\begin{array}{c}\text { LOD } \\
\left(\mathrm{ng} \mathrm{mL}^{-1}\right)\end{array}$ & $\begin{array}{c}\mathrm{LOQ} \\
\left(\mathrm{ng} \mathrm{mL}^{-1}\right)\end{array}$ & $\begin{array}{l}\text { RSD } \\
(\%)\end{array}$ \\
\hline Methyl isobutyl ketone & $y=805869 x+5 E+07$ & 0.9463 & 10026208 & 8058691 & 0.74 & 2.48 & 0.9 \\
\hline 2-Heptanone & $y=5 E+06 x+3 E+08$ & 0.9785 & 2623366 & $5.00 \mathrm{E}+06$ & 0.32 & 1.05 & 0.2 \\
\hline Dimethylbenzene & $y=1 E+07 x+4 E+08$ & 0.9835 & 310653 & $1 \mathrm{E}+07$ & 0.02 & 0.06 & 4.0 \\
\hline Isopropylbenzene & $y=6 E+06 x+3 E+08$ & 0.9544 & 29827885 & $6.00 \mathrm{E}+06$ & 3.00 & 9.94 & 5.5 \\
\hline Trimethylbenzene & $y=2 E+07 x+7 E+08$ & 0.984 & 681651 & $2.00 \mathrm{E}+07$ & 0.02 & 0.07 & 2.9 \\
\hline Phenol & $y=7591881 x-2 E+07$ & 0.9892 & 15207533 & 7591881 & 1.20 & 4.00 & 6.6 \\
\hline tert-Butylbenzene & $y=6 E+06 x+2 E+08$ & 0.9855 & 42115421 & $6.00 \mathrm{E}+06$ & 4.20 & 14.04 & 9.5 \\
\hline alpha-Terpinene & $y=1 E+07 x+1 E+08$ & 0.9647 & 47849916 & $1.00 \mathrm{E}+07$ & 2.80 & 9.56 & 9.8 \\
\hline Limonene & $y=2 E+07 x+3 E+08$ & 0.9599 & 136306146 & $2.00 \mathrm{E}+07$ & 4.00 & 13.64 & 10.5 \\
\hline Ocimene & $y=9 E+06 x+8 E+07$ & 0.9827 & 19865104 & $9.00 \mathrm{E}+06$ & 1.32 & 4.42 & 6.3 \\
\hline Acetophenone & $y=1 E+07 x-1 E+07$ & 0.9944 & 42166192 & $1,00 \mathrm{E}+07$ & 2.60 & 8.44 & 2.2 \\
\hline Cresol & $y=3 E+06 x-5 E+07$ & 0.9554 & 8847603 & $3,00 \mathrm{E}+06$ & 1.76 & 5.90 & 2.2 \\
\hline $\begin{array}{l}1,3,5-\text { Triisopropyl } \\
\text { benzene }\end{array}$ & $y=1 E+07 x+2 E+08$ & 0.9883 & 12613977 & $1.00 \mathrm{E}+07$ & 3.78 & 12.6 & 2.64 \\
\hline 5-Nonanone & $y=2 E+07 x+5 E+08$ & 0.9938 & 62313078 & $2.00 \mathrm{E}+07$ & 1.86 & 6.24 & 2.6 \\
\hline Terpinolene & $y=1 E+07 x+2 E+08$ & 0.9783 & 10613977 & $1.00 \mathrm{E}+07$ & 0.64 & 2.12 & 2.1 \\
\hline Isophorone & $y=5 E+06 x-5 E+06$ & 0.9981 & 10035259 & $5.00 \mathrm{E}+06$ & 1.20 & 4.02 & 0.9 \\
\hline Camphor & $y=1 E+07 x+4 E+08$ & 0.9894 & 76927561 & $1.00 \mathrm{E}+07$ & 4.60 & 15.38 & 2.4 \\
\hline Benzothiazole & $y=1 E+07 x-9 E+07$ & 0.9888 & 89652655 & $1.00 \mathrm{E}+07$ & 5.40 & 17.94 & 5.2 \\
\hline
\end{tabular}

Repeatability was expressed by means of six replicates $(n=6)$ of the standard mixture in concentration of $25 \mathrm{ng} \mathrm{mL}^{-1}$. The results showed a good repeatability, the relative standard deviation RSD being situated under 15$16 \%$, the maximum accepted at the concentration level less than $100 \mathrm{ppb}$ [15]. The method provide also a good linearity with a coefficient of determination 
$\left(\mathrm{R}^{2}\right)$ ranging between 0.95 and 0.99 , a low LOD $\left(0.02-54 \mathrm{ng} \mathrm{mL} \mathrm{L}^{-1}\right)$ and LOQ (0.05-17.94 $\mathrm{ng} \mathrm{mL}^{-1}$ ) respectively.

The combination of columns chosen for the separation provides a good resolution between the standard compound mixture (Figure 1).

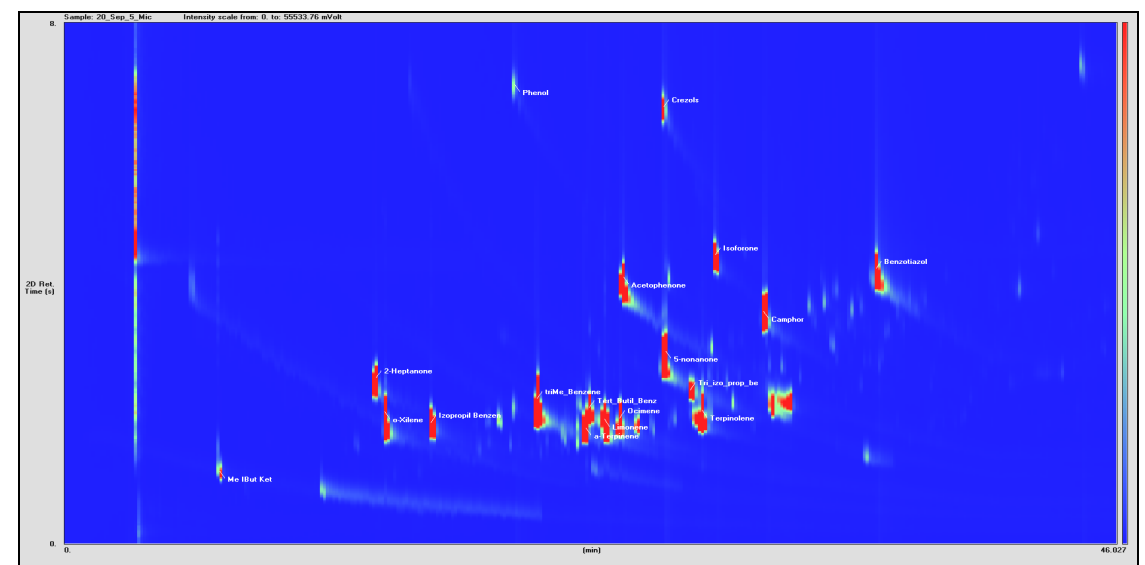

Figure 1. GCxGC chromatogram of the standard mixture

\subsection{Analysis of municipal landfill leachate samples}

The extraction and the analysis of volatile organic compounds in municipal landfill leachate samples were done under the conditions described in the Experimental part. The results of the performed experiment showed that the landfill leachate contains a huge number of volatile organic compounds with different polarities which are well distributed on the GCxGC chromatogram (Figure 2).

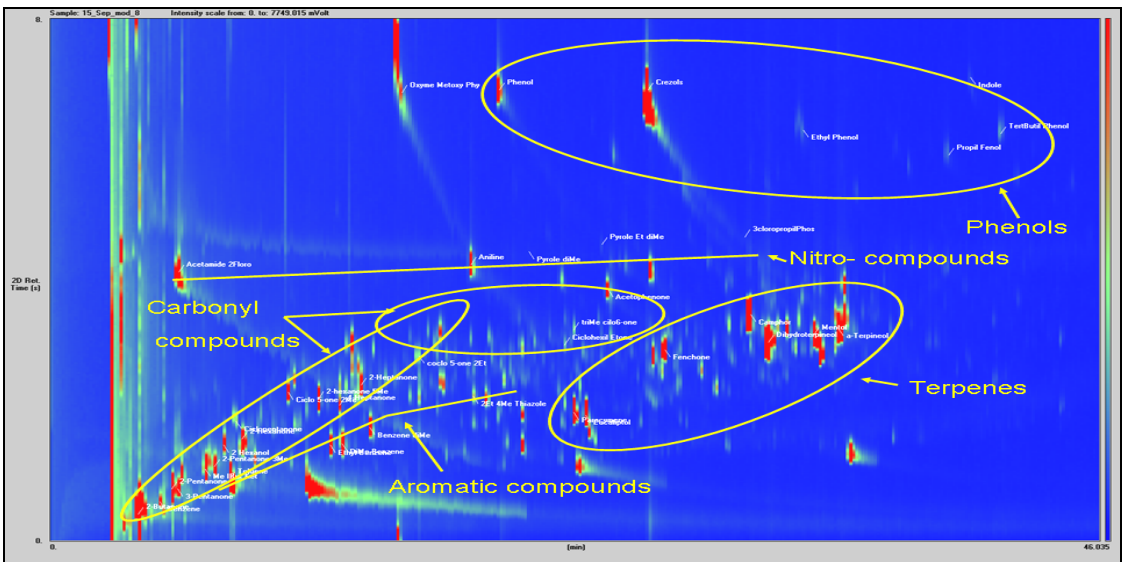

Figure 2. GCXGC chromatogram of the municipal landfill leachate sample and the classes of the identified compounds 
It can be observed that the compounds are grouped on the families according to their physical and chemical proprieties.

Using the standard mixtures, the retention parameters (retention time in the first dimension (RT $1^{\text {st }} \mathrm{D}$ ) and retention time in the second dimension (RT $\left.2^{\text {nd }} \mathrm{D}\right)$ ) and the mass spectra, in the leachate sample 40 compounds were identified. Their name, molecular formula and retention parameters are presented in Table 2. It should be mention that only the compounds with similarity of mass spectra compared with NIST mass spectra library exceeding $70 \%$ were taken into consideration.

Table 2. Compounds identified according to standard mixture, their mass spectra and retention parameters

\begin{tabular}{|c|c|c|c|}
\hline Component name/abbreviation & Molecular formula & RT 1st D (min) & RT 2nd D (sec) \\
\hline 2-Butanone & & 3.733 & 0.50 \\
\hline Benzene & & 4.872 & 0.64 \\
\hline 2-Pentanone & & 5.333 & 0.82 \\
\hline 3-Pentanone & & 5.412 & 0.93 \\
\hline $\begin{array}{l}\text { Fluoroacetamide I } \\
\text { (Acetamide 2Floro) }\end{array}$ & & 5.467 & 4.09 \\
\hline $\begin{array}{l}\text { Methyl isobutyl ketone / } \\
\text { (Me IBut Ket) }\end{array}$ & & 6.800 & 1.09 \\
\hline $\begin{array}{l}\text { 3-Methyl-2-pentanone / } \\
\text { (2-Pentanone 3Me) }\end{array}$ & & 7.200 & 1.07 \\
\hline Hexanal & & 7.600 & 1.55 \\
\hline Toluene & & 8.000 & 1.00 \\
\hline 2-Hexanone & & 8.400 & 1.55 \\
\hline $\begin{array}{l}\text { 2-Methylcyclopentanone / } \\
\text { (Ciclo 5-one 2Me) }\end{array}$ & & 10.667 & 2.52 \\
\hline $\begin{array}{l}\text { 5-Methyl-2-hexanone / } \\
\text { (2-hexanone 5Me) }\end{array}$ & & 11.600 & 2.02 \\
\hline Ethylbenzene / (Ethyl Benzene) & & 12.267 & 1.43 \\
\hline
\end{tabular}


M. S. BELDEAN-GALEA, D. THIÉBAUT, J. VIAL, V. COMAN

\begin{tabular}{|c|c|c|c|}
\hline Component name/abbreviation & Molecular formula & RT 1st D (min) & RT 2nd D (sec) \\
\hline 4-Heptanone & & 12.667 & 2.14 \\
\hline $\begin{array}{l}\text { 1, 2-dimethylbenzene / } \\
\text { (DiMe Benzene) }\end{array}$ & & 12.800 & 1.45 \\
\hline 2-Heptanone & & 13.600 & 2.55 \\
\hline $\begin{array}{l}\text { 1, 3-dimethylbenzene / } \\
\text { (Benzene diMe) }\end{array}$ & & 14.000 & 1.84 \\
\hline $\begin{array}{l}\text { Methyl N- } \\
\text { hydroxybenzenecarboximidoate/ } \\
\text { (Oxyme Metoxy Phy) }\end{array}$ & & 15.067 & 7.25 \\
\hline $\begin{array}{l}\text { 2-Ethylcyclopentanone / } \\
\text { (coclo 5-one 2Et) }\end{array}$ & & 16.000 & 2.86 \\
\hline Aniline & & 18.400 & 4.41 \\
\hline $\begin{array}{l}\text { 2-Ethyl-4-methylthiazole / } \\
\text { (2Et 4Me Thiazole) }\end{array}$ & & 18.533 & 2.25 \\
\hline Phenol & & 19.600 & 6.93 \\
\hline $\begin{array}{l}\text { 2,4-Dimethylpyrrole / } \\
\text { (Pyrole diMe) }\end{array}$ & & 21.200 & 4.82 \\
\hline $\begin{array}{l}\text { Cyclohexyl Ethanone / } \\
\text { (Ciclohexil Etone) }\end{array}$ & & 22.987 & 3.02 \\
\hline $\begin{array}{l}\text { 3,3,5-Trimethylcyclohexanone/ } \\
\text { (triMe cilo6-one) }\end{array}$ & & 22.933 & 3.27 \\
\hline p-cymene / (Paracimene) & & 23.600 & 1.77 \\
\hline Eucalyptol / (Eucaliptol) & & 24.267 & 1.82 \\
\hline
\end{tabular}


IDENTIFICATION OF COMPLEX VOLATILE ORGANIC COMPOUNDS IN MUNICIPAL LANDFILL ...

\begin{tabular}{|c|c|c|c|}
\hline Component name/abbreviation & Molecular formula & RT 1st D (min) & RT 2nd D (sec) \\
\hline Acetophenone & & 24.400 & 3.91 \\
\hline $\begin{array}{l}\text { 3-Ethyl-2,4-dimethylpyrrole / } \\
\text { (Pyrole Et diMe) }\end{array}$ & & 24.400 & 4.57 \\
\hline Cresol / (Crezols) & & 26.133 & 6.61 \\
\hline Fenchone & & 26.833 & 2.84 \\
\hline Camphor & & 30.667 & 3.43 \\
\hline Dihydroterpineol & & 31.467 & 3.16 \\
\hline Ethyl Phenol & & 32.800 & 6.25 \\
\hline Menthol / (Mentol) & & 33.600 & 3.07 \\
\hline$\alpha$-Terpineol & & 34.400 & 3.50 \\
\hline Propyl Phenol / (Propil Fenol) & & 39.067 & 5.95 \\
\hline Indole & & 40.000 & 7.11 \\
\hline $\begin{array}{l}\text { 4-tert Butylphenol / } \\
\text { (TertButil Phenol) }\end{array}$ & & 41.923 & 6.12 \\
\hline
\end{tabular}

It can be also observed that in the analyzed sample the most prevalent compounds are carbonyl group compounds, phenolic compounds, terpenes and aromatic and alkyl aromatic hydrocarbons. Also, nitrogen 
containing compounds such as fluoroacetamide, aniline, 2,4-dimethylpyrrole, 3-ethyl-2,4-dimethylpyrrole, 2-ethyl-4-methylthiazole, methyl Nhydroxybenzenecarboximidoate have been identified.

Many other compounds could not be identified due to the technical limitation of the instrument. However, the developed method has a big potential and provides information that are difficult to obtain using classical chromatographic methods.

Moreover, the obtained results are in agreement with other studies referring to the odorants of municipal landfill leachate [8-12], but this study provides a better identification of the compounds due to their GCxGC arrangement.

\section{CONCLUSIONS}

The developed procedure provides a very sensitive method for the analysis of volatile organic compounds in municipal landfill leachate.

Identification of the compounds is improved due to the grouping of the compounds on the families according their physical and chemical proprieties.

The most prevalent families of the identified compounds are carbonyl group compounds, phenolic compounds, terpenes, aromatic and alkyl aromatic hydrocarbons and nitrogen-containing compounds.

SPME-GCXGC-qMS could be a good and green alternative for the screening of volatile organic compounds in municipal landfill leachate, being able to provide better information about the compounds responsible for odors.

\section{EXPERIMENTAL SECTION}

\subsection{Reagents and solutions}

For the qualitative and quantitative analysis a standard mixture containing different classes of organic compounds in concentration of 100 $\mu \mathrm{g} \mathrm{mL}^{-1}$ dissolved in a solvent mixture of $n$-hexane:acetone $(1: 1 \mathrm{v} / \mathrm{v})$ was used. The composition of the standard mixture is given in Table 1. The standard mixture was prepared from pure substances, of analytical grade purity, purchased from Sigma Aldrich, Supelco and Fluka. The calibration standard solutions in concentration of $10,25,50,100$ and $150 \mathrm{ng} \mathrm{mL}^{-1}$ were prepared by dilution of different volumes of standard mixture in $5 \mathrm{~mL}$ of Milli-Q water. Acetone and $n$-hexane $(99.99 \%$ purity) were provided from Merck (Germany) and helium in purity of $99.9999 \%$ from Air Liquide, France. The Milli-Q water was prepared using a Milli-Q Plus water system from Millipore (USA). 


\subsection{Instrumentation, chromatographic and SPME conditions}

For the analysis of volatile organic compounds in municipal landfill leachate, a Thermo Trace GC $\times$ GC gas chromatograph equipped with a dual $\mathrm{CO}_{2}$ cryogenic modulator and coupled to a quadrupole mass spectrometer (qMS) model ThermolSQ (Courtaboeuf, France) was used. Helium of high purity at a constant pressure of $156 \mathrm{kPa}$ was used as carrier gas. The mass spectrometer frequency of acquisition was $50 \mathrm{~Hz}$, and the SCAN mode was used for data collection, setting a mass range from 45 to $250 \mathrm{~m} / \mathrm{z}$. The ionization was performed by Electron Impact lonization using a voltage of $70 \mathrm{eV}$. The ion source temperature was $210^{\circ} \mathrm{C}$ and $280^{\circ} \mathrm{C}$ for the transfer line. The inlet temperature was set at $280^{\circ} \mathrm{C}$ and the injection was made in split mode using a split ration of 10 .

For the separation, a Factor Four VF-1 ms column (100\% dimethylpolysiloxane), $30 \mathrm{~m} \times 0.25 \mathrm{~mm}$ ID, $0.25 \mu \mathrm{m}$ film thickness (Varian) was used in the first dimension and a DB-1701 column ((14\%-cyanopropylphenyl)-methylpolysiloxane), $1.5 \mathrm{~m} \times 0.10 \mathrm{~mm}$ ID, $0.10 \mu \mathrm{m}$ film thickness (Agilent) was used for the second dimension. The separation of compounds was performed with a gradient temperature program, by a heating of $2.0^{\circ} \mathrm{C} / \mathrm{min}$ from 40 to $120^{\circ} \mathrm{C}$, with 5 minutes final hold time. The modulation period was 8 seconds and the initial off-set was 0.5 second.

The data acquisition was performed using the X-Calibur software and the $\mathrm{GC} \times \mathrm{GC}$ representation was realized by the Chrom-Card software. The identification of the compounds was done comparing the obtained mass spectra with those from NIST (classical) mass spectral library.

The solid phase microextraction (SPME) of the target compounds was performed using a SDVB/carbowax/pdms fiber, $20 \mathrm{~mm}$ length using a TriPlus Autosampler. For the extraction, the following conditions were used: incubation temperature $60^{\circ} \mathrm{C}$ in constant mode, extraction time 10 minutes and desorption time 15 minutes.

For the analysis of volatile organic compounds in real samples, 5 $\mathrm{mL}$ of municipal landfill leachate collected from a municipal solid waste landfill from Romania was used. The extraction was done according to the protocol described above.

\section{ACKNOWLEDGEMENTS}

This work was performed in the frame of the Romania - France Bilateral Cooperation, Program Brâncuși, Project no. 774/2014 funded by UEFISCDI - Roumania and Project no 32654NJ funded by Campus-France. 


\section{REFERENCES}

1. S. Budi, B.A. Suliasih, M.S. Othman, L.Y. Heng, S. Surif, Waste Management, 2016, 55, 231.

2. C. Oman, P.-A. Hynning, Environmental Pollution, 1993, 80, 265.

3. T.H. Christensen, P. Kjeldsen, H.J. Albrechtsen, H.J. Heron, P.H. Nielsen, P.L. Bjerg, P.E. Holm, Critical Reviews in Environmental Science and Technology, 1994, 24, 119.

4. R.J. Slack, J.R. Gronow, N. Voulvoulis, Science of the Total Environment, 2005, 337, 119.

5. D. Kulikowska, E. Klimiuk, Bioresource Technology, 2008, 99, 5981.

6. M.S. Beldean-Galea, J. Vial, D. Thiébaut, Central European Journal of Chemistry, 2013, 11(10), 1563.

7. E. Borrás, L.A.Tortajada-Genaro, A. Muñoz, Talanta, 2016, 148, 472.

8. M. Palmiotto, E. Fattore, V. Paiano, G. Celeste, A. Colombo, E. Davoli, Environment International, 2014, 68, 16.

9. D. Ying, C. Chuanyu, H. Bin, X. Yueen, Z. Xuejuan, C. Yingxu, W. Weixiang, Waste Management, 2012, 32, 317.

10. B. Scaglia, V. Orzi, A. Artola, X. Font, E. Davoli, A. Sanchez, F. Adani, Bioresource Technology, 2011, 102, 4638.

11. R. Chiriac, J. Carré, Y. Perrodin, L. Fine, J.-M. Letoffe, Journal of Hazardous Materials, 2007, 149, 249.

12. R. Chiriac, J. Carré, Y. Perrodin, H. Vaillant, S. Gasso, P. Miele, Atmospheric Environment, 2009, 43, 1926.

13. E. Davoli, M.L. Gangai, L. Morselli, D. Tonelli, Chemosphere, 2003, 51, 357.

14. J.-J. Fang, N. Yang, D.-Y. Cen, L.-M. Shao, P.-J. He, Waste Management, 2012, 32, 1401.

15. European Community Document, SANCO No. 3030/99, rev. 4, 11/07/2000 https://ec.europa.eu/food/sites/food/files/plant/docs/ pesticides_ppp_appproc_guide_phys-chem-ana_tech-mat-preps.pdf 